\title{
Influence of oral glutamine supplementation on survival outcomes of patients treated with concurrent chemoradiotherapy for locally advanced non-small cell lung cancer
}

Erkan Topkan ${ }^{1 *}$, Cem Parlak', Savas Topuk ${ }^{1}$ and Berrin Pehlivan ${ }^{2}$

\begin{abstract}
Background: Glutamine (Gln) supplementation during concurrent chemoradiotherapy (C-CRT) effectively reduces the incidence and severity of acute radiation-induced esophagitis (RIE). However, there are concerns that Gln might stimulate tumor growth, and therefore negatively impact the outcomes of anticancer treatment. We retrospectively investigated the effect of co-administration of oral Gln during C-CRT on survival outcomes of patients with stage IIIB non-small cell lung carcinoma (NSCLC). We additionally evaluated role of oral Gln in preventing C-CRT-induced weight change, acute and late toxicities.

Methods: The study included 104 patients: 56 (53.8\%) received prophylactic powdered Gln (GIn+) orally at a dose of $10 \mathrm{~g} / 8 \mathrm{~h}$ and 48 (46.2\%) did not receive Gln (Gln-) and served as controls. The prescribed radiation dose to the planning target volume was 66 Gy in 2-Gy fractions. Primary endpoints of progression-free survival (PFS), local/ regional progression-free survival (LRPFS), and overall survival (OS) were correlated with status of GIn supplementation.
\end{abstract}

Results: Oral Gln was well tolerated except for mild nausea/vomiting in 14 (25.0\%) patients. There was no C-CRT-related acute or late grade 4-5 toxicity. Administration of Gln was associated with a decrease in the incidence of grade 3 acute radiation-induced esophagitis (RIE) (7.2\% vs. $16.7 \%$ for GIn+ vs. GIn-; $p=0.02)$ and late-RIE (0\% vs. 6.3\%; $p=0.06)$, a reduced need for unplanned treatment breaks (7.1\% vs. 20.8\%; $p=0.04$ ), and reduced incidence of weight loss (44.6\% vs. 72.9\%; $p=0.002)$. At a median follow-up of 24.2 months (range 9.2-34.4) the median OS, LRPFS, and PFS for GIn+ vs. GIn- cohorts were 21.4 vs. 20.4 ( $p=0.35), 14.2$ vs.11.3 ( $p=0.16)$, and 10.2 vs. 9.0 months $(p=0.11)$, respectively.

Conclusion: In our study, supplementation with GIn during C-CRT had no detectable negative impact on tumor control and survival outcomes in patients with Stage IIIB NSCLC. Furthermore, Gln appeared to have a beneficial effect with respect to prevention of weight loss and unplanned treatment delays, and reduced the severity and incidence of acute- and late-RIE.

Keywords: Concurrent chemotherapy, Radiotherapy, Glutamine supplementation, Lung cancer, Survival outcome, Tumor growth

\footnotetext{
* Correspondence: docdretopkan@gmail.com

${ }^{1}$ Department of Radiation Oncology, Baskent University Adana Medical

Faculty, Adana, Turkey

Full list of author information is available at the end of the article
} 


\section{Background}

Complications related to concurrent chemoradiotherapy (C-CRT) such as acute radiation-induced esophagitis (ARIE) may cause significant morbidity and unplanned treatment delays in patients with locally advanced nonsmall cell lung carcinoma (LA-NSCLC). Such complications not only impact the quality of life but also reduce the ability to escalate the dose of radiotherapy (RT) to more effective levels, resulting in potential reductions in tumor control and survival rates. Improvements in target definition and the advent of sophisticated RT techniques, combined with elimination of elective irradiation of clinically uninvolved lymphatics, have significantly reduced the volume of normal tissue exposed to highdose radiation with a resultant reduction in incidence and severity of treatment-related toxicity [1]. However, because of the need to irradiate subclinical tumor extension, normal tissue toxicity and its consequences likely will remain a challenge for the foreseeable future [2].

Pharmacologic radioprotection can efficiently prevent, or at least reduce, the incidence and/or severity of acute radiation-induced esophagitis (ARIE) and related complications during C-CRT of LA-NSCLC. One agent with potential radioprotective properties is glutamine (Gln), the primary oxidative fuel of the gut epithelium that is necessary for maintenance of its structural integrity $[3,4]$. Although Gln is continuously provided by skeletal muscles during hypercatabolic states such as cancer, over time marked Gln depletion develops that cannot be overcome by increased synthesis [4]. This results in compromised acid-base balance, immune functions, and epithelial integrity in the gut [5]. Additionally, because of its antioxidant activity in normal tissues, depletion of glutathione (GSH), a by-product of Gln metabolism, may increase the extent of tissue damage caused by $\mathrm{C}$ CRT $[3,6,7]$. In this context, exogenous Gln supplementation not only normalizes Gln levels in the body but also selectively increases GSH levels in normal tissue, which may explain its selective radioprotective function [3,6-8]. Two recent studies, including one from our institution, revealed a beneficial role of oral Gln in the reduction of ARIE incidence and severity, as well as maintenance of body weight, in LA-NSCLC patients treated with C-CRT $[9,10]$.

It is important to investigate the effect of any agent that reduces treatment-related toxicities on tumor tissue. As an example, amifostine, which is a strong radioprotector, was found to have no detrimental effects on survival outcome in a recent meta-analysis by Bourhis et al. [11], suggesting no tumor protection or growth stimulating action. On the contrary, erythropoietin, which has been used successfully for stimulation of erythropoiesis in various cancers, negatively impacted survival outcomes for most tumor types [12]. Considering these two conflicting results of two agents, commonly practiced in radiation oncology clinics, because growth of various cell lines of tumor and non-tumor origin is a function of Gln availability [13-15], there is increasing concern that Gln might stimulate tumor growth and therefore negatively impact outcomes of anticancer treatment. This issue has never been addressed in the setting of NSCLC. Therefore, in this retrospective analysis, we comparatively assessed the impact of Gln supplementation during CCRT on survival outcomes in LA-NSCLC patients. We additionally evaluated role of oral Gln in preventing CCRT-induced weight change, acute and late toxicities.

\section{Methods \\ Study subjects}

The database maintained by our institution was retrospectively searched to identify all patients with LANSCLC who had undergone C-CRT between January 2008 and December 2010. Inclusion criteria were: histopathologically proven NSCLC, stage IIIB disease by $18 \mathrm{~F}-$ fluorodeoxyglucose positron emission tomography (FDG PET-CT), age $\geq 18$ and $<70$, Karnofsky Performance Status (KPS) $\geq 70$, available treatment charts and hospital computerized data, RT data sets for dosimetric calculations, no prior history of thoracic RT (TRT) or chemotherapy, no contraindication for C-CRT, no pretreatment dysphagia or ingestion difficulties, body mass index (BMI) $\geq 18 \mathrm{~kg} / \mathrm{m}^{2}$, and no dietary supplementation except for Gln in the prescribed dose and schedule. The study population contained 104 patients who met the above criteria.

The study was approved by the institutional review board of Baskent University before collection of patient information and was conducted according to the principles of the Declaration of Helsinki and the rules of Good Clinical Practice.

\section{Concurrent chemoradiotherapy}

In our department, FDG-PET-CT fusion-based threedimensional treatment planning is the standard of care for LA-NSCLC patients. Target volume definition, dose specification, and normal tissue tolerance limits for eligible patients were as described elsewhere [10]. Briefly, TRT was administered through anteroposterior-posteroanterior (AP-PA) portals with individualized multi-leaf collimator blocks for initial planning target volume (PTV1) up to 46 Gy, followed by an off-spinal cord oblique boost dose of up to 66 Gy for PTV2. All patients received daily TRT for 5 days a week with 2 Gy per fraction using high energy linear accelerators and concurrent treatment with one of the two following chemotherapy combinations: $\mathrm{CD}$, cisplatin $\left(80 \mathrm{mg} / \mathrm{m}^{2}\right)$ and docetaxel $\left(80 \mathrm{mg} / \mathrm{m}^{2}\right)$, on days 1 , 22 , and $43(\mathrm{n}=49)$; or $\mathrm{CV}$, cisplatin $\left(80 \mathrm{mg} / \mathrm{m}^{2}\right)$ and 
vinorelbine $\left(30 \mathrm{mg} / \mathrm{m}^{2}\right.$, days 1 and 8$)$ every 21 days for 3 cycles $(n=55)$.

\section{Glutamine supplementation}

Our current institutional policy is to recommend prophylactic Gln supplementation for all patients scheduled to undergo TRT. We prefer to use oral Gln powder to reduce the incidence and severity of ARIE. Fifty-six patients (53.8\%) received powdered Gln (Nestle Nutrition, Istanbul, Turkey) at a dose of $10 \mathrm{~g} / 8 \mathrm{~h}$ orally in water or fruit juice, starting 1 week before TRT and continuing for 2 weeks after completion of RT. The remaining 48 patients $(46.2 \%)$, who did not receive Gln due to economic reasons or patients' self-choice, served as controls. Based on institutional standards, patients receiving Gln were followed by experienced nurses for adherence to protocol, general nutritional status, and adverse events throughout the treatment period. The dose of $30 \mathrm{~g} /$ day was selected based on available literature, which reported its efficacy in reducing the incidence and severity of ARIE and weight loss in LA-NSCLC patients treated with C-CRT $[9,10]$ and in lowering the incidence of grade 2-4 mucositis in patients treated with cytotoxic chemotherapy $[16,17]$. Patients who did not use Gln were nourished with diets that were achievable based on their socioeconomic status to improve their nutritional status.

\section{Patient evaluation and toxicity scoring}

For each patient, we calculated weight change (WC), percent WC (PWC), and body mass index (BMI) change between baseline and post-treatment measures using available chart records. Weight change, the absolute difference between pre- and post-treatment weight measures, is a parameter that is independent of pretreatment weight and has the potential to underestimate the value of pre-treatment body mass [18]. Therefore, we also calculated weight change as a percentage relative to pre-treatment weight (PWC). Nausea and vomiting was considered Gln-induced only if reported within the 1-week period of Gln administration before commencement of C-CRT, and graded according to RTOG scoring [19]. All patients were examined at weekly intervals for ARIE incidence and weight changes during C-CRT. ARIE was graded by a radiation oncologist according to RTOG-ARIE scoring criteria [19], and the reported grade of ARIE reflected the worst grade observed (Table 1). The calculated and reported data were used for intra- and intergroup comparisons. After completion of C-CRT, patients were examined at weekly intervals for the first month to allow for the possibility of an early "esophagitis peak" and bimonthly thereafter.
Table 1 Radiation Therapy Oncology Group (RTOG) acute radiation-induced esophageal morbidity scoring criteria

\begin{tabular}{ll}
\hline Grade & Description \\
\hline 0 & No change \\
\hline 1 & $\begin{array}{l}\text { Mild dysphagia or odynophagia, requiring topical } \\
\text { anesthetic, non-narcotic agents, or soft diet }\end{array}$ \\
\hline 2 & $\begin{array}{l}\text { Moderate dysphagia or odynophagia, requiring } \\
\text { narcotic agents or liquid diet }\end{array}$ \\
\hline 4 & $\begin{array}{l}\text { Severe dysphagia or odynophagia with dehydration } \\
\text { or weight loss ( }>15 \% \text { of pretreatment baseline), } \\
\text { requiring nasogastric feeding }\end{array}$ \\
\hline 5 & Complete stricture, ulceration, perforation or fistula \\
\hline
\end{tabular}

\section{Response assessment and follow-up}

Treatment response was assessed by re-staging FDGPET-CT scans from the 8-week post-C-CRT follow-up according to EORTC-1999 guidelines [20] (summarized in Table 2), and at 3-month intervals thereafter. The 8week time interval for the first follow-up FDG-PET-CT was arbitrarily chosen as the shortest possible time for response assessment based on our national health insurance politics, rather than on evidence-based practice. Thereafter, patients were monitored by evaluation of blood count/chemistry every 8-12 weeks. Additional abdominal ultrasound and/or CT, chest CT, cranial magnetic resonance imaging, and FDG-PET-CT were performed as indicated.

\section{Statistical methods}

Statistical analyses were performed based on patient stratification according to their Gln supplementation status (Gln+ and Gln-). Frequency distributions were used to describe categorical variables and mean, median, and ranges were used for quantitative variables. Demographic features were compared between the Gln+ and Gln- cohorts using a Chi-square test. The effects of Gln on acute and late radiation-induced esophageal toxicity, BMI change, WC, and PWC during treatment, and need for hospitalization and/or treatment breaks were comparatively analyzed. As these issues were previously addressed in our previous study, for this current study, the primary endpoints were determined to be differences in overall survival (OS), locoregional progression-free survival (LRPFS), and progression-free survival (PFS) between the two cohorts. OS, LRPFS, and PFS were calculated as the time between the first day of C-CRT and the date of death/last visit for OS, the date of local or regional relapse or the date of death/last visit for LRPFS, and any type of local/regional or distant progression of disease or the date of death/last visit for PFS. Survival analysis was performed by the Kaplan-Meier method and the survival curves of subsets were compared with 
Table 2 Proposed EORTC 1999 criteria for clinical and subclinical response assessment by PET-CT

\begin{tabular}{ll}
\hline Response & Definition \\
\hline Progressive metabolic disease & $\begin{array}{l}\text { An increase in }{ }^{18} \mathrm{FDG} \text { tumor SUV of greater than } 25 \% \text { within the tumor } \\
\text { region defined on the baseline scan, visible increase in the extent of }{ }^{18} \mathrm{FDG}\end{array}$ \\
$\begin{array}{ll}\text { tumor uptake }(>20 \% \text { in the longest dimension) or the appearance of new } \\
{ }^{18} \mathrm{FDG} \text { uptake in metastatic lesions }\end{array}$ \\
\hline Stable metabolic disease & $\begin{array}{l}\text { An increase in tumor }{ }^{18} \mathrm{FDG} \text { SUV of less than } 25 \% \text { or a decrease of less } \\
\text { than } 15 \% \text { and no visible increase in extent of }{ }^{18} \mathrm{FDG} \text { tumor uptake }(>20 \% \text { in } \\
\text { the longest dimension) }\end{array}$ \\
\hline Partial metabolic response & $\begin{array}{l}\text { A reduction of a minimum of } 15-25 \% \text { in tumor }{ }^{18} \mathrm{FDG} \text { SUV after one cycle } \\
\text { of chemotherapy, and greater than } 25 \% \text { after more than one treatment cycle }\end{array}$ \\
\hline Complete metabolic response & $\begin{array}{l}\text { Complete resolution of }{ }^{18} \mathrm{FDG} \text { uptake within the tumor volume so that it } \\
\text { was indistinguishable from surrounding normal tissue }\end{array}$ \\
\hline
\end{tabular}

two-sided log-rank tests. All tests were two-tailed, and a p-value $<0.05$ was considered significant.

\section{Results}

Pretreatment characteristics of patients and disease are shown in Table 3. In general C-CRT was well tolerated in both cohorts. The unique acute toxicities experienced during the first week of Gln administration prior to initiation of C-CRT were mild nausea in 10 (17.9\%) patients and vomiting in $4(7.1 \%)$ patients, both of which were successfully treated with metoclopramide. During the course of C-CRT there was no grade $\geq 3$ nausea or vomiting, and the rates of grade 1-2 nausea and vomiting were $32.1 \%$ and $19.6 \%$ respectively for Gln+ cohorts and $29.2 \%$ and $16.7 \%$ for Gln- cohorts ( $p>0.05$ for each).

No grade 4-5 ARIE was reported in Gln+ or Glncohorts. As shown in Table 4, comparative analysis revealed a significantly lower incidence of grade 3 ARIE in the Gln+ cohort than in the Gln- cohort $(7.2 \%$ vs. $16.7 \% ; \mathrm{p}=0.02$ ). Diagnosis of maximum grade ARIE was delayed by 8 days with the use of Gln (24.5 vs. 16.4 days, $\mathrm{p}=0.001)$. Unplanned treatment delays, either by frequency or time, were also significantly lower in the Gln+ cohort. Hospitalization was needed in $5(4.8 \%)$ patients: $3(6.3 \%)$ in the Gln- cohort and $2(3.6 \%)$ in the Gln+ cohort $(p=0.14)$, and all patients were able to complete C-CRT with appropriate treatment and supportive measures as indicated. Over the long-term, no grade 4/5 late esophageal toxicity (LET) was reported in either cohort. The incidence of grade 2/3 LET was higher in the Glncohort than the Gln+ cohort (12.6\% vs. $3.6 \%)$, approaching statistical significance $(\mathrm{p}=0.06)$.

Although all other supportive measures were similar between cohorts, Gln- patients experienced significant weight loss, negative PWC, and negative BMI change, whereas Gln+ patients maintained or gained weight at the end of the C-CRT course, as reflected in the PWC and BMI measurements (Table 4).

At a median follow-up of 24.2 months (range 5.2$37.8), 45$ patients $(36.9 \%)$ were alive [23 $\mathrm{Gln}+(41.1 \%)$ and $22 \mathrm{Gln}-(45.8 \%)]$, and $17(16.3 \%)$ of these were free of disease progression [10 Gln+ (17.9\%) and 7 Gln(14.6\%)]. Analysis of response rates according to EORTC-1999 criteria and relapse patterns revealed no significant difference between the two cohorts $(\mathrm{p}>0.05$; Table 5). Partial response and distant relapses were the most common response and relapse patterns in both Gln+ and Gln- cohorts.

Median OS, LRPFS, and PFS for the entire population were 20.9 (95\% CI: 19.5-22.3), 12.7 (95\% CI: 11.5-13.5), and 9.7 months (95\% CI: 9.0-10.4), respectively. Corresponding 2-and 3-year survival estimates were 34.9\% and $25.4 \%$ for OS; $16.8 \%$ and $16.8 \%$ for LRPFS; and $16.1 \%$ and $16.1 \%$ for PFS, respectively. As shown in Figure 1 and Table 6, intergroup comparisons between Gln+ and Gln- cohorts revealed no statistically significant differences in median 2- and 3-year OS, LRPFS, and PFS.

\section{Discussion}

Despite the potential unpredictable disadvantages of any retrospective analysis, in the dose and schedule utilized here, present results showed that besides being beneficial in prevention of weight loss, unplanned treatment delays, severity and incidence of acute and late RIE, coadministration of Gln during C-CRT has no detectable negative impact on tumor control and survival outcomes in patients with stage IIIB NSCLC.

One strategy to reduce radiation-induced normal tissue toxicity is the use of protective pharmacologic agents shortly before and/or during the course of RT/C-CRT. Recent preclinical studies revealed that Gln, the primary fuel of enterocytes and lymphocytes, not only plays a crucial role in maintaining gut integrity and cellular immunity $[3,21-24]$ but also protects against acute and late radiation-induced injury by inhibiting bacterial translocation and stimulating production of the antioxidant GSH [25-29]. Clinically, oral Gln reduces the incidence and severity of RT- and/or chemotherapy-induced mucosal injury at various tumor sites, including the esophagus in NSCLC [9,10,30-32]. Similarly, our current findings showed that Gln prophylaxis was associated 
Table 3 Pretreatment patient and disease characteristics

\begin{tabular}{|c|c|c|c|c|}
\hline Characteristic & $\begin{array}{c}\text { All } \\
(\mathrm{N}=104)\end{array}$ & $\begin{array}{c}\text { Glutamine }(+) \\
(\mathrm{N}=56)\end{array}$ & $\begin{array}{c}\text { Glutamine }(-) \\
(\mathrm{N}=48)\end{array}$ & P-value \\
\hline \multicolumn{5}{|l|}{ Age (years) } \\
\hline Median (Range) & $57.6(33-69)$ & $58.7(41-69)$ & $56.5(33-69)$ & 0.41 \\
\hline \multicolumn{5}{|l|}{ Gender (N; \%) } \\
\hline Male & $67(64.4)$ & $35(62.5)$ & $32(66.7)$ & 0.62 \\
\hline Female & 37 (35.6) & $21(37.5)$ & $16(33.3)$ & \\
\hline \multicolumn{5}{|l|}{ Histology (N; \%) } \\
\hline Squamous cell & $64(61.5)$ & $34(60.7)$ & $30(62.5)$ & 0.81 \\
\hline Adeno & $40(38.5)$ & $22(39.3)$ & $18(37.5)$ & \\
\hline \multicolumn{5}{|l|}{ KPS (N; \%) } \\
\hline $90-100$ & $58(55.8)$ & 30 (53.6) & $28(58.3)$ & 0.76 \\
\hline $70-80$ & $46(44.2)$ & $26(46.4)$ & $20(41.7)$ & \\
\hline \multicolumn{5}{|l|}{ TN-stage (N; \%) } \\
\hline T1N3 & $7(6,7)$ & $4(7,1)$ & $3(6,3)$ & 0.38 \\
\hline $\mathrm{T} 2 \mathrm{~N} 3$ & $13(12.5)$ & $6(10.7)$ & $7(14.5)$ & \\
\hline T3N3 & $17(16.3)$ & $10(17.8)$ & $7(14.5)$ & \\
\hline T4N0 & $11(10.6)$ & $6(10.7)$ & $5(10.4)$ & \\
\hline $\mathrm{T4N1}$ & $16(15.4)$ & $8(14.3)$ & $8(16.7)$ & \\
\hline T4N2 & $18(17.3)$ & $10(17.9)$ & $8(16.7)$ & \\
\hline$\overline{\mathrm{T} 4 \mathrm{~N} 3}$ & $22(21.2)$ & $12(21.5)$ & $10(20.9)$ & \\
\hline \multicolumn{5}{|l|}{ T-stage (N; \%) } \\
\hline 1 & $7(6.7)$ & $4(7.1)$ & $3(6.3)$ & 0.33 \\
\hline 2 & $13(12.5)$ & $6(10.7)$ & $7(14.5)$ & \\
\hline 3 & $17(16.3)$ & $10(17.8)$ & $7(14.5)$ & \\
\hline 4 & $67(64.5)$ & $36(64.4)$ & $31(64.7)$ & \\
\hline \multicolumn{5}{|l|}{$\mathrm{N}$-stage (N; \%) } \\
\hline 0 & $11(10.6)$ & $6(10.7)$ & $5(10.4)$ & 0.58 \\
\hline 1 & $16(15.4)$ & $8(14.3)$ & $8(16.7)$ & \\
\hline 2 & $18(17.3)$ & $10(17.9)$ & $8(16.7)$ & \\
\hline 3 & $59(56.7)$ & $32(57.1)$ & $25(58.1)$ & \\
\hline \multicolumn{5}{|l|}{ Bulk of T (N; \%) } \\
\hline$\leq 3.0 \mathrm{~cm}$ & $8(7.7)$ & $3(5.4)$ & $5(10.4)$ & 0.42 \\
\hline $3.01-5.0 \mathrm{~cm}$ & $15(14.4)$ & $8(14.3)$ & $7(14.6)$ & \\
\hline $5.01-7.0 \mathrm{~cm}$ & $43(41.3)$ & $24(42.9)$ & 19 (39.6) & \\
\hline$>7.0 \mathrm{~cm}$ & 38 (36.6) & $21(37.4)$ & $17(35.4)$ & \\
\hline \multicolumn{5}{|c|}{ Bulk of largest $N(\mathrm{~N} ; \%)$} \\
\hline$\leq 2.0 \mathrm{~cm}$ & $58(55.8)$ & $30(53.7)$ & $28(58.3)$ & 0.22 \\
\hline$>2.0 \mathrm{~cm}$ & $46(44.2)$ & $26(46.3)$ & $20(41.7)$ & \\
\hline \multicolumn{5}{|l|}{ Chemotherapy } \\
\hline Platin - docetaxel & $46(44.2)$ & $24(42.9)$ & $22(45.8)$ & 0.79 \\
\hline Platin - vinorelbine & $58(55.8)$ & $32(57.1)$ & $26(54.2)$ & \\
\hline \multicolumn{5}{|l|}{ Weight (kg) } \\
\hline Median (range) & $66.3(50.5-87.6)$ & $65.9(50.5-86.8)$ & $67.2(54.6-87.6)$ & 0.37 \\
\hline \multicolumn{5}{|l|}{ BMI (kg/m2) } \\
\hline Median (range) & $22.1(18.4-27.8)$ & $21.8(18.4-27.6)$ & $22.3(18.8-27.8)$ & 0.91 \\
\hline
\end{tabular}

Abbreviations: BMI: Body mass index; KPS: Karnofsky performance score; N: Node; T: Tumor. 
Table 4 Treatment outcomes

\begin{tabular}{|c|c|c|c|}
\hline Characteristic & $\begin{array}{c}\text { Glutamine }(+) \\
(\mathrm{N}=56)\end{array}$ & $\begin{array}{c}\text { Glutamine }(-) \\
(\mathrm{N}=48)\end{array}$ & $\begin{array}{c}\mathrm{P}- \\
\text { value }\end{array}$ \\
\hline \multicolumn{4}{|c|}{ Maximum grade ARIE (N; \%) } \\
\hline $0-1$ & $40(71.4)$ & $21(43.7)$ & 0.02 \\
\hline 2 & 37.0 & 34.2 & \\
\hline 3 & 27.8 & 22.8 & \\
\hline $4-5$ & $0(0)$ & $0(0)$ & \\
\hline \multicolumn{4}{|c|}{ Grade 2-3 ARIE onset (days) } \\
\hline Median & 24.5 & 16.4 & 0.001 \\
\hline Range & $(17-32)$ & $(9-23)$ & \\
\hline Treatment delay $(\mathrm{N} ; \%)$ & $4(7.1)$ & $10(20.8 \%)$ & 0.04 \\
\hline Hospitalization & $2(3.6)$ & $3(6.3)$ & 0.14 \\
\hline \multicolumn{4}{|l|}{ Weight change (N; \%) } \\
\hline No change or gain & $31(55.4)$ & $13(27.1)$ & 0.002 \\
\hline Loss & $25(44.6)$ & $35(72.9)$ & \\
\hline \multicolumn{4}{|l|}{ Weight change (kg) } \\
\hline Median & 2.6 & -3.3 & $<0.00$ \\
\hline Range & (-3.1 to 7.6$)$ & $(-9.7$ to 2.3$)$ & \\
\hline \multicolumn{4}{|l|}{ Weight change (\%) } \\
\hline Median & 3.94 & -4.91 & $<0.00$ \\
\hline Range & $(-4.7$ to 11.5$)$ & $(-14.4$ to 3.4$)$ & \\
\hline \multicolumn{4}{|l|}{ LET (maximum grade) } \\
\hline 2 & $2(3.6)$ & $3(6.3)$ & 0.06 \\
\hline 3 & $0(0)$ & $3(6.3)$ & \\
\hline $4-5$ & $0(0)$ & $0(0)$ & \\
\hline
\end{tabular}

Abbreviations: ARIE: Acute radiation-induced esophagitis; LET: Late esophageal toxicity.

with significantly reduced rates of grade 3 ARIE incidence ( $7.2 \%$ vs.16.8\%; $\mathrm{p}=0.02)$, and delayed onset of maximum grade ARIE (24.5 vs. 16.4 days; $\mathrm{p}=0.001)$ with no add on toxicity.

Considering its selective protective function in normal non-cancerous tissues, ease of use, and mild and easily manageable toxicity profile, Gln appears to be an ideal radioprotector. However, there are concerns that Gln may protect tumor cells, or even promote tumor growth, when used in conjunction with anticancer treatment [13-15]. To our knowledge, no previous clinical study has specifically addressed the influence of Gln on tumor control and survival outcomes when administered during C-CRT in NSCLC patients, and the results of studies

Table 5 Locoregional response and relapse characteristics for patients with and without glutamine supplementation

\begin{tabular}{|c|c|c|c|c|}
\hline Characteristic & $\begin{array}{c}\text { All } \\
(\mathrm{N}=104)\end{array}$ & $\begin{array}{c}\text { Glutamine }(+) \\
(\mathrm{N}=56)\end{array}$ & $\begin{array}{c}\text { Glutamine }(-) \\
(\mathrm{N}=48)\end{array}$ & $\begin{array}{c}\mathrm{P}- \\
\text { value }\end{array}$ \\
\hline \multicolumn{5}{|c|}{ Locoregional response $(\mathrm{N} ; \%)$} \\
\hline Complete & $15(14.4)$ & $8(14.3)$ & $7(14.5)$ & 0.79 \\
\hline Partial & $34(32.7)$ & $18(32.1)$ & $16(33.4)$ & 0.62 \\
\hline Stable & $28(26.9)$ & $16(28.6)$ & $12(25.0)$ & 0.31 \\
\hline Progression & $27(26.0)$ & $14(25.0)$ & $13(27.1)$ & 0.43 \\
\hline \multicolumn{5}{|l|}{ Relapse pattern (N; \%) } \\
\hline None & $19(18.3)$ & $10(17.9)$ & $9(18.8)$ & 0.42 \\
\hline Locoregional & $20(19.2)$ & $10(17.9)$ & $10(20.8)$ & 0.59 \\
\hline Distant & $46(44.2)$ & $25(44.6)$ & $21(43.7)$ & 0.30 \\
\hline Locoregional + distant & 19 (18.3) & $11(19.6)$ & $8(16.7)$ & 0.24 \\
\hline
\end{tabular}




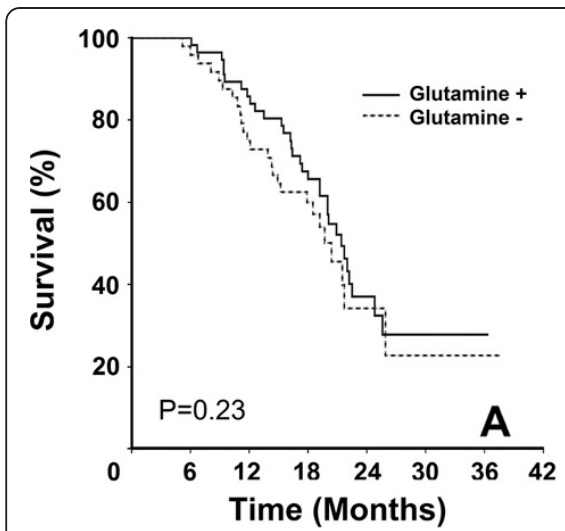

No. patients at risk

$$
\begin{array}{rrrrrrr}
-56 & 56 & 48 & 37 & 26 & 24 & 24 \\
\cdots . . .48 & 46 & 36 & 29 & 23 & 22 & 22
\end{array}
$$

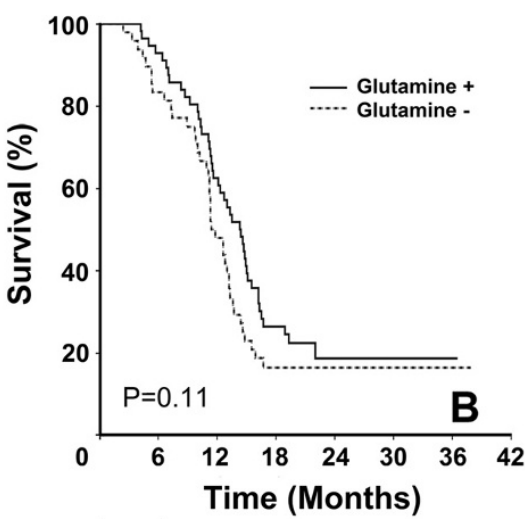

No. patients at risk

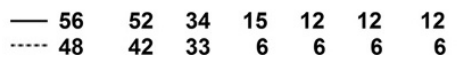

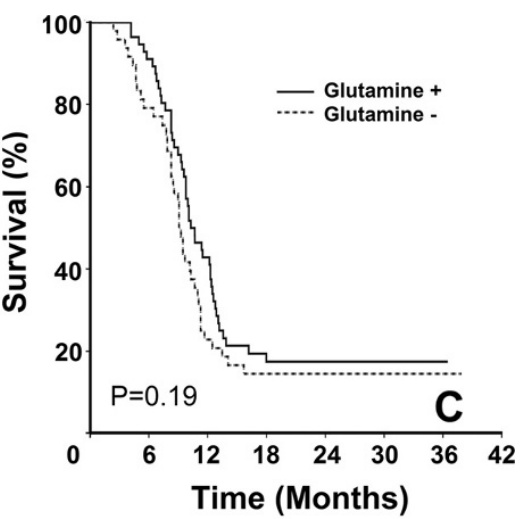

No. patients at risk

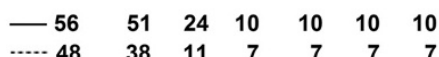

Figure 1 Comparative survival analyses between Gln+ and Gln- cohorts. A: Overall survival (OS); B: Progression-free Survival (PFS); C: Local Regional Progression-free Survival (LRPFS). Solid line: Gln+; Dashed line: Gln-.

on other tumor sites are conflicting [17,33-36]. Therefore, this is the first report of the effects of Gln on survival outcomes, and indirectly, tumor growth kinetics of LA-NSCLC in the era of RT/C-CRT.

Although the fact that human tumors exhibit a 5- to 10-fold faster rate of Gln consumption than normal healthy tissues [37-39] might suggest that supplemental Gln would promote growth of tumor calls [13-15], Gln did not stimulate tumor growth or negatively affect the outcome of any type of anti-tumor treatment in this study and previously published reports $[8,21,22,40,41]$. In experimental studies, Gln supplementation has repeatedly been shown to replete Gln stores in muscle with no promotion of tumor growth which was proved by absence of any notable increment in tumor DNA

Table 6 Survival estimates according to prophylactic glutamine use

\begin{tabular}{|c|c|c|c|}
\hline Survival & $\begin{array}{c}\text { Glutamine }(+) \\
(\mathrm{N}=56)\end{array}$ & $\begin{array}{l}\text { Glutamine }(-) \\
(\mathrm{N}=48)\end{array}$ & $\begin{array}{c}\mathrm{P}- \\
\text { value }\end{array}$ \\
\hline \multicolumn{4}{|l|}{ Overall } \\
\hline Median (months) & 21.4 & 20.4 & 0.23 \\
\hline 2-year (\%) & 37.0 & 34.2 & \\
\hline 3-year (\%) & 27.8 & 22.8 & \\
\hline \multicolumn{4}{|c|}{ Locoregional progression free } \\
\hline Median (months) & 11.3 & 14.2 & 0.11 \\
\hline 2-year (\%) & 18.7 & 16.4 & \\
\hline 3-year (\%) & 18.7 & 16.4 & \\
\hline \multicolumn{4}{|l|}{ Progression free } \\
\hline Median (months) & 10.2 & 9.0 & 0.19 \\
\hline 2-year (\%) & 17.5 & 14.6 & \\
\hline 3-year (\%) & 17.5 & 14.6 & \\
\hline
\end{tabular}

content $[8,21,22,40]$. Furthermore, Fahr and colleagues [41] demonstrated that Gln gavage and pair-fed food combination was associated with a 30\% increment in natural killer (NK) cell activity and a $40 \%$ reduction in tumor growth. Use of Gln in conjunction with chemotherapy and/or RT has been investigated in only a limited number of clinical trials. In a large randomized, double-blind, placebo-controlled study [33], oral Gln supplementation was associated with significantly reduced mouth pain and, more importantly, improved survival rates at 28 days in 193 patients undergoing autologous or allogeneic bone marrow transplant. In a similar patient group, Schloerb and Skikne [34] reported significantly improved long-term survival with parenteral Gln supplementation. In the setting of RT or C-CRT, the few published studies concentrated on the radioprotective actions of Gln without considering its potential impact on tumor growth and survival outcomes $[9,10,32,42,43]$. Consistent with recently reported CCRT studies without Gln [44-49], the similar PFS, LRPFS, and OS for Gln+ and Gln- cohorts observed in the current study demonstrated no association between tumor growth stimulation and high-dose Gln administered during C-CRT of LA-NSCLC patients.

If Gln is not provided exogenously tumor cells can successfully manipulate host metabolism to cover their needs, therefore artificial depletion of Gln cannot stop, or even retard, tumor growth. In fact, Gln-deprivation increases tumor cell survival through the induction of pro-angiogenic, pro-metastatic, pro-inflammatory, and tumor motility factors such as VEGF, IL-8, and $\mathrm{NF}_{-\mathrm{K}} \mathrm{B}$ [4]. Moreover, lack of supplementary Gln can lead to serious Gln depletion, which is closely associated with impaired physiological functions such as disturbances in 
mucosal integrity, immune competence, maintenance of normal tissue GSH levels, and inhibition of bacterial translocation, resulting in serious medical complications. Therefore, exogenous Gln utilized here appears to improve the general metabolic condition and host defense mechanisms, and decrease the C-CRT-induced toxicity and related detrimental effects on quality of life measures and clinical outcomes.

One important consequence of dose-limiting acute toxicities of RT, and particularly C-CRT, in LA-NSCLC patients is the need for unplanned treatment breaks, which mandates reductions in doses of chemotherapy/RT and/or prolongs the overall treatment time with the potential to induce accelerated tumor repopulation [50]. Overall, any prolongation in treatment course is strongly associated with significantly reduced efficacy of C-CRT and therefore reduced rates of locoregional control and survival [51]. Our study showed that Gln significantly reduced the incidence and delayed the onset of grade $\geq 3$ ARIE, reduced the need for unplanned treatment breaks, and reduced hospitalization. Although our study failed to show a significant survival advantage, further studies with larger study cohorts and sufficient statistical power to detect a moderate survival advantage are warranted.

The present study has several limitations. First, as for any retrospective study, unpredictable biases may have influenced our results. Second, heterogeneity due to inclusion of both adeno- and squamous cell cancer histologies, together with the limited cohort size, probably decreased the statistical power to identify a subgroup that may have benefited from Gln supplementation in terms of tumor control and survival outcomes. Third, although not significant statistically, the survival rates of the Gln+ cohort were higher than those of the Gln- cohort at all time points, suggesting that patients who received Gln supplementation tended to do better than those who did not. This may be partly associated with the small sample size and relatively short follow-up period and should be further addressed in larger studies with a longer follow-up period. Finally, although our institutional policy mandates arrangement of nutritional status of patients prior to treatment, nutritional differences are strongly associated with general feeding behaviors and socioeconomic status and cannot easily be controlled between the groups which may also affected our results.

\section{Conclusion}

Our analysis showed that supplemental use of Gln during C-CRT has no detectable negative impact on tumor control and survival outcomes in patients with Stage IIIB NSCLC, but rather might prevent weight loss and unplanned treatment delays and reduce the severity and incidence of acute and late RIE. However, prospective randomized studies with larger cohorts and statistical power or comprehensive meta-analyses are warranted to conclude more relevantly on this continuously discussed specific issue of oncology.

\section{Competing interests}

We have no personal or financial conflict of interest and have not entered into any agreement that could interfere with our access to the data on the research, or upon our ability to analyze the data independently, to prepare manuscripts, and to publish them.

\section{Authors' contributions}

Study conception and design: ET. Provision of study materials or patients: ET, ST, CP. Collection and assembly of data: ET, CP, BP. Data analysis and interpretation: ET, CP. Manuscript writing: ET, CP. Final approval of manuscript: $E T, C P, S T, B P$.

\section{Acknowledgements}

Results of this study were presented at the 29th European Society for Therapeutic Radiology and Oncology Congress (ESTRO 29): 12-16 September 2010, Barcelona, Spain.

\section{Author details}

${ }^{1}$ Department of Radiation Oncology, Baskent University Adana Medical Faculty, Adana, Turkey. ${ }^{2}$ Department of Radiation Oncology, Memorial Health Group, Medstar Antalya Hospital, Antalya, Turkey.

Received: 24 February 2012 Accepted: 18 October 2012 Published: 31 October 2012

\section{References}

1. Chapet O, Fraas BA, Ten Haken RK: Multiple fields may offer better esophagus sparing without increased probability of lung toxicity in optimized IMRT of lung tumors. Int J Radiat Oncol Biol Phys 2006, 65:255-265

2. Citrin D, Cotrim AP, Hyodo F, Baum BJ, Krishna MC, Mitchell JB: Radioprotectors and mitigators of radiation-induced normal tissue injury. Oncologist 2010, 15(4):360-71.

3. Savarese DM, Savy G, Vahdat L, Wischmeyer PE, Corey B: Prevention of chemotherapy and radiation toxicity with glutamine. Cancer Treat Rev 2003, 29(6):501-513.

4. Kuhn KS, Muscaritoli M, Wischmeyer P, Stehle P: Glutamine as indispensable nutrient in oncology: experimental and clinical evidence. Eur J Nutr 2010, 49(4):197-210.

5. Kapadia C, Muhlbacher F, Smith R: Alterations in glutamine metabolism in response to operative stress and food deprivation. Surg Forum 1982, 33:19-21.

6. Rouse K, Nwokedi E, Woodliff JE, Epstein J, Klimberg VS: Glutamine enhances selectivity of chemotherapy through changes in glutathione metabolism. Ann Surg 1995, 221(4):420-426.

7. Klimberg VS, Nwokedi B: LF H: Does glutamine facilitate chemotherapy while reducing its toxicity? Surg Forum 1991, 42:16-18.

8. Carretero J, Obrador E, Pellicer JA, Pascual A, Estrela JM: Mitochondrial glutathione depletion by glutamine in growing tumor cells. Free Radic Biol Med 2000, 29(9):913-923.

9. Algara M, Rodriguez N, Vinals P, Lacruz M, Foro P, Reig A, Quera J, Lozano J, Fernandez-Velilla E, Membrive I, et al: Prevention of radiochemotherapyinduced esophagitis with glutamine: results of a pilot study. Int J Radiat Oncol Biol Phys 2007, 69(2):342-349.

10. Topkan E, Yavuz MN, Onal C, Yavuz AA: Prevention of acute radiationinduced esophagitis with glutamine in non-small cell lung cancer patients treated with radiotherapy: evaluation of clinical and dosimetric parameters. Lung Cancer 2009, 63(3):393-399.

11. Bourhis J, Blanchard P, Maillard E, Brizel DM, Movsas B, Buentzel J, Langendijk JA, Komaki R, Swan Leong S, Levendag P, et al: Effect of amifostine on survival among patients treated with radiotherapy: a meta-analysis of individual patient data. J Clin Oncol 2011, 29(18):2590-2597.

12. Bohlius J, Schmidlin K, Brillant C, Schwarzer G, Trelle S, Seidenfeld J, Zwahlen M, Clarke M, Weingart O, Kluge $S$, et al: Recombinant human 
erythropoiesis-stimulating agents and mortality in patients with cancer: a meta-analysis of randomised trials. Lancet 2009, 373(9674):1532-1542.

13. Eagle H: Nutritional needs of mammalian cells in tissue culture. Science 1935, 122:501.

14. Collins CL, Wasa M, Souba WW, Abcouwer SF: Determinants of glutamine dependence and utilization by normal and tumor-derived breast cell lines. J Cell Physiol 1998, 176:166-178.

15. Sauer LA, Dauchy RT: Ketone body, glucose, lactic acid, and amino acid utilization by tumors in vivo in fasted rats. Cancer Res 1983, 43:3497-3503.

16. Choi K, Lee SS, Oh SJ, Lim SY, Lim SY, Jeon WK, Oh TY, Kim JW: The effect of oral glutamine on 5-fluorouracil/ leucovorin-induced mucositis/ stomatitis assessed by intestinal permeability test. Clin Nutr 2007, 26:57-62.

17. Wang WS, Lin JK, Lin TC, Chen WS, Jiang JK, Wang HS, Chiou TJ, Liu JH, Yen $\mathrm{CC}$, Chen PM: Oral glutamine is effective for preventing oxaliplatininduced neuropathy in colorectal cancer patients. Oncologist 2007, 12:312-319.

18. Monteforte MJ, Turkelson CM: Bariatric surgery for morbid obesity. Obes Surg 2000, 10(5):391-401.

19. Cox JD, Stez J, Pajak TF: Toxicity criteria of the radiation therapy oncology group (RTOG) and the European organization for research and treatment of cancer (EORTC). Int I Radiat Oncol Biol Phys 1995, 31:1341-1346

20. Young H, Baum R, Cremerius U, Herholz K, Hoekstra O, Lammertsma AA, Pruim J, Price P: Measurement of clinical and subclinical tumour response using [18F]-fluorodeoxyglucose and positron emission tomography: review and 1999 EORTC recommendations. European Organization for Research and Treatment of Cancer (EORTC) PET Study Group. Eur J Cancer 1999, 35(13):1773-1782

21. Bartlett DL, Charland S, Torosian MH: Effect of glutamine on tumor and host growth. Ann Surg Oncol 1995, 2(1):71-76.

22. Klimberg VS, Souba WW, Salloum RM, Plumley DA, Cohen FS, Dolson DJ, Bland Kl, Copeland EM 3rd: Glutamine-enriched diets support muscle glutamine metabolism without stimulating tumor growth. J Surg Res 1990, 48(4):319-323.

23. van der Hulst RR, van Kreel BK, von Meyenfeldt MF, Brummer RJ, Arends JW, Deutz NE, Soeters PB: Glutamine and the preservation of gut integrity. Lancet 1993, 341(8857):1363-1365.

24. Shewchuk LD, Baracos VE, Field CJ: Dietary L-glutamine supplementation reduces the growth of the Morris Hepatoma 7777 in exercise-trained and sedentary rats. J Nutr 1997, 127(1):158-166.

25. Klimberg VS, Souba WW, Dolson DJ, Salloum RM, Hautamaki RD, Plumley DA, Mendenhall WM, Bova FJ, Khan SR, Hackett RL, et al: Prophylactic glutamine protects the intestinal mucosa from radiation injury. Cancer 1990, 66(1):62-68.

26. Klimberg V: How glutamine protects the gut during irradiation. J Crit Care Nutr 1996, 3:21-25.

27. Jensen JC, Schaefer R, Nwokedi E, Bevans DW 3rd, Baker ML, Pappas AA, Westbrook KC, Klimberg VS: Prevention of chronic radiation enteropathy by dietary glutamine. Ann Surg Oncol 1994, 1(2):157-163.

28. Souba WW, Klimberg VS, Hautamaki RD, Mendenhall WH, Bova FC, Howard $\mathrm{RJ}$, Bland KI, Copeland EM: Oral glutamine reduces bacterial translocation following abdominal radiation. J Surg Res 1990, 48(1):1-5.

29. Salman B, Oguz M, Akmansu M, Bebitoglu I, Akca G, Sultan N, Emre U, Kerem M, Yilmaz U: Effect of timing of glutamine-enriched enteral nutrition on intestinal damage caused by irradiation. Adv Ther 2007, 24(3):648-661.

30. Huang EY, Leung SW, Wang CJ, Chen HC, Sun LM, Fang FM, Yeh SA, Hsu $\mathrm{HC}$, Hsiung $\mathrm{CY}$ : Oral glutamine to alleviate radiation-induced oral mucositis: a pilot randomized trial. Int J Radiat Oncol Biol Phys 2000, 46(3):535-539.

31. Yoshida S, Matsui M, Shirouzu Y, Fujita H, Yamana H, Shirouzu K: Effects of glutamine supplements and radiochemotherapy on systemic immune and gut barrier function in patients with advanced esophageal cancer. Ann Surg 1998, 227(4):485-491.

32. Cerchietti LC, Navigante AH, Lutteral MA, Castro MA, Kirchuk R, Bonomi M, Cabalar ME, Roth B, Negretti G, Sheinker B, et al: Double-blinded, placebocontrolled trial on intravenous L-alanyl-L-glutamine in the incidence of oral mucositis following chemoradiotherapy in patients with head-andneck cancer. Int J Radiat Oncol Biol Phys 2006, 65(5):1330-1337.
33. Anderson PM, Ramsay NK, Shu XO, Rydholm N, Rogosheske J, Nicklow R, Weisdorf DJ, Skubitz KM: Effect of low-dose oral glutamine on painful stomatitis during bone marrow transplantation. Bone Marrow Transplant 1998, 22(4):339-344.

34. Schloerb PR, Skikne BS: Oral and parenteral glutamine in bone marrow transplantation: a randomized, double-blind study. JPEN J Parenter Enteral Nutr 1999, 23(3):117-122.

35. Vahdat L, Papadopoulos K, Lange D, Leuin S, Kaufman E, Donovan D, Frederick D, Bagiella E, Tiersten A, Nichols G, et al: Reduction of paclitaxelinduced peripheral neuropathy with glutamine. Clin Cancer Res 2001, 7(5):1192-1197.

36. Li Y, Yu Z, Liu F, Tan L, Wu B, Li J: Oral glutamine ameliorates chemotherapy-induced changes of intestinal permeability and does not interfere with the antitumor effect of chemotherapy in patients with breast cancer: a prospective randomized trial. Tumori 2006, 92(5):396-401.

37. Bode BP, Kaminski DL, Souba WW, Li AP: Glutamine transport in isolated human hepatocytes and transformed liver cells. Hepatology 1995, 21(2):511-520.

38. Fischer $\mathrm{CP}$, Bode BP: WW S: Adaptive alterations in cellular metabolism with malignant transformation. Ann Surg 1998, 227(2):627-634.

39. Knox WE, Horowitz ML, Friedell GH: The proportionality of glutaminase content to growth rate and morphology of rat neoplasms. Cancer Res 1969, 29(3):669-680

40. Obrador E, Carretero J, Esteve JM, Pellicer JA, Pascual A, Petschen I, Estrela $J M$ : Glutamine potentiates TNF-alpha-induced tumor cytotoxicity. Free Radic Biol Med 2001, 31(5):642-650.

41. Fahr MJ, Kornbluth J, Blossom S, Schaeffer R, Klimberg VS, Harry M: Vars Research Award. Glutamine enhances immunoregulation of tumor growth. JPEN J Parenter Enteral Nutr 1994, 18(6):471-476.

42. El-Malt M, Ceelen W, Boterberg T, Claeys G, de Hemptinne B, de Neve W, Pattyn P: Does the addition of glutamine to total parenteral nutrition have beneficial effect on the healing of colon anastomosis and bacterial translocation after preoperative radiotherapy? Am J Clin Oncol 2003, 26(3):e54-59.

43. Kozelsky TF, Meyers GE, Sloan JA, Shanahan TG, Dick SJ, Moore RL, Engeler GP, Frank AR, McKone TK, Urias RE, et al: Phase III double-blind study of glutamine versus placebo for the prevention of acute diarrhea in patients receiving pelvic radiation therapy. J Clin Oncol 2003, 21(9):1669-1674

44. Yamamoto N, Nakagawa K, Nishimura Y, Tsujino K, Satouchi M, Kudo S, Hida T, Kawahara M, Takeda K, Katakami N, et al: Phase III study comparing second- and third-generation regimens with concurrent thoracic radiotherapy in patients with unresectable stage III non-small-cell lung cancer: West Japan Thoracic Oncology Group WJTOG0105. J Clin Oncol 2010, 28(23):3739-3745.

45. Segawa Y, Kiura K, Takigawa N, Kamei H, Harita S, Hiraki S, Watanabe Y, Sugimoto K, Shibayama T, Yonei T, et al: Phase III trial comparing docetaxel and cisplatin combination chemotherapy with mitomycin, vindesine, and cisplatin combination chemotherapy with concurrent thoracic radiotherapy in locally advanced non-small-cell lung cancer: OLCSG 0007. J Clin Oncol 2010, 28(20):3299-3306.

46. Blumenschein GR Jr, Paulus R, Curran WJ, Robert F, Fossella F, Werner-Wasik M, Herbst RS, Doescher PO, Choy H, Komaki R: Phase II study of cetuximab in combination with chemoradiation in patients with stage IIIA/B non-small-cell lung cancer: RTOG 0324. J Clin Oncol 2011, 29(17):2312-2318

47. Curran WJ Jr, Paulus R, Langer CJ, Komaki R, Lee JS, Hauser S, Movsas B, Wasserman T, Rosenthal SA, Gore E, et al: Sequential vs. concurrent chemoradiation for stage III non-small cell lung cancer: randomized phase III trial RTOG 9410. J Natl Cancer Inst 2011, 103(19):1452-1460.

48. Brade A, Bezjak A, MacRae R, Laurie S, Sun A, Cho J, Leighl N, Pearson S, Southwood B, Wang $L$, et al: Phase I trial of radiation with concurrent and consolidation pemetrexed and cisplatin in patients with unresectable stage IIIA/B non-small-cell lung cancer. Int J Radiat Oncol Biol Phys 2011, 79(5):1395-1401.

49. Govindan R, Bogart J, Stinchcombe T, Wang X, Hodgson L, Kratzke R, Garst J, Brotherton T, Vokes EE: Randomized phase II study of pemetrexed, carboplatin, and thoracic radiation with or without cetuximab in patients with locally advanced unresectable non-small-cell lung cancer: Cancer and Leukemia Group B trial 30407. J Clin Oncol 2011, 29(23):3120-3125. 
50. El Sharouni SY, Kal HB, Battermann JJ: Accelerated regrowth of non-smallcell lung tumours after induction chemotherapy. Br J Cancer 2003, 89(12):2184-2189.

51. Koukourakis M, Hlouverakis G, Kosma L, Skarlatos J, Damilakis J,

Giatromanolaki A, Yannakakis D: The impact of overall treatment time on the results of radiotherapy for nonsmall cell lung carcinoma. Int J Radiat Oncol Biol Phys 1996, 34(2):315-322.

doi:10.1186/1471-2407-12-502

Cite this article as: Topkan et al:: Influence of oral glutamine supplementation on survival outcomes of patients treated with concurrent chemoradiotherapy for locally advanced non-small cell lung cancer. BMC Cancer 2012 12:502.

\section{Submit your next manuscript to BioMed Central and take full advantage of:}

- Convenient online submission

- Thorough peer review

- No space constraints or color figure charges

- Immediate publication on acceptance

- Inclusion in PubMed, CAS, Scopus and Google Scholar

- Research which is freely available for redistribution 